\title{
Towards improved health service quality in Tanzania: contribution of a supportive supervision approach to increased quality of primary healthcare
}

Sabine Renggli $1{ }^{1} 2^{*}$ D, Iddy Mayumana ${ }^{3}$, Dominick Mboya ${ }^{3}$, Christopher Charles ${ }^{3}$, Christopher Mshana ${ }^{3}$, Flora Kessy ${ }^{3}$, Tracy R. Glass ${ }^{1,2}$, Christian Lengeler ${ }^{1,2}$, Alexander Schulze ${ }^{4}$, Ann Aerts $^{5}$ and Constanze Pfeiffer ${ }^{1,2}$

\begin{abstract}
Background: Universal Health Coverage only leads to the desired health outcomes if quality of health services is ensured. In Tanzania, quality has been a major concern for many years, including the problem of ineffective and inadequate routine supportive supervision of healthcare providers by council health management teams. To address this, we developed and assessed an approach to improve quality of primary healthcare through enhanced routine supportive supervision.

Methods: Mixed methods were used, combining trends of quantitative quality of care measurements with qualitative data mainly collected through in-depth interviews. The former allowed for identification of drivers of quality improvements and the latter investigated the perceived contribution of the new supportive supervision approach to these improvements.

Results: The results showed that the new approach managed to address quality issues that could be solved either solely by the healthcare provider, or in collaboration with the council. The new approach was able to improve and maintain crucial primary healthcare quality standards across different health facility level and owner categories in various contexts.

Conclusion: Together with other findings reported in companion papers, we could show that the new supportive supervision approach not only served to assess quality of primary healthcare, but also to improve and maintain crucial primary healthcare quality standards. The new approach therefore presents a powerful tool to support, guide and drive quality improvement measures within council. It can thus be considered a suitable option to make routine supportive supervision more effective and adequate.
\end{abstract}

Keywords: Quality of care, Quality improvement approach, Tanzania, Electronic tool, Supportive supervision, Universal health coverage

\footnotetext{
* Correspondence: sabine.renggli@bluewin.ch

${ }^{1}$ Department of Epidemiology and Public Health, Swiss Tropical and Public

Health Institute, P.O. Box, 4002, Basel, Switzerland

${ }^{2}$ University of Basel, Basel, Switzerland

Full list of author information is available at the end of the article
}

(c) The Author(s). 2019 Open Access This article is distributed under the terms of the Creative Commons Attribution 4.0 International License (http://creativecommons.org/licenses/by/4.0/), which permits unrestricted use, distribution, and reproduction in any medium, provided you give appropriate credit to the original author(s) and the source, provide a link to the Creative Commons license, and indicate if changes were made. The Creative Commons Public Domain Dedication waiver (http://creativecommons.org/publicdomain/zero/1.0/) applies to the data made available in this article, unless otherwise stated. 


\section{Background}

Since the publication of the World Health Report in 2010 there is growing ambition in many countries for progress towards Universal Health Coverage (UHC) $[1,2]$. This was further stimulated through the formulation of UHC as one of the prominent targets of the health-related Sustainable Development Goal 3 [3]. However, there is no benefit to UHC if poor quality of care leads to unwillingness of people to use services [4]. And even if services are accessed and used, studies suggest that poor quality is undermining health outcomes [5-8]. Consequently, health services need to be of sufficient quality to achieve the desired outcomes and therefore improving quality must be of highest priority $[4,9,10]$. One of the main challenges resulting in weak quality in low- and middle-income countries is the lack of enough, well-trained and motivated staff with adequate financial and physical resources to provide basic health services [11, 12]. Another problem is insufficient resources and/or ineffective and inefficient allocation of limited resources [12,13]. Additionally, upon quality assessments district managers and healthcare providers seldom receive feedback on the performance of their facilities. As a result, assessment results are rarely translated into appropriate quality improvement measures [14]. It was moreover reported that many assessments seemed to measure donor funded programs rather than country owned initiatives, leading to parallel monitoring structures that burden the system $[14,15]$. In Tanzania, given the expansion of health services, quality of care has become a major concern for many years [16]. Some of the issues are low standards of hygiene and sanitation, insufficient health infrastructure, poor healthcare waste disposal, low motivation of health workers, inadequate adherence to professional and ethical conduct, as well as a know-do gap amongst health workers $[16,17]$. The last point refers to the gap between what health workers know and what they actually do [18]. Missing ownership of quality improvement measures at facility level and poor feedback on quality developments at council level are further issues found in Tanzania [16, 17]. Also, Council Health Management Teams (CHMTs), who are in charge of managing services provided within their council, are often conducting routine supportive supervision of healthcare providers inadequately and ineffectively $[16,17,19]$. Amongst other things, the main problems of routine CHMT supportive supervision are infrequency, fragmentation, incompleteness and inconsistency as well as a focus on quantity (reviewing record books) instead of quality (service delivery processes) [16, 20-27]. Supportive supervision was shown to promote quality improvements in several low resource settings, but strongly depends on the way it is conducted [28-38]. Already in the Tanzanian Health Sector Strategic Plan III (HSSP) (2009-2015) the need to put quality improvement systems in place was stipulated [39]. The topic received even greater attention in the subsequent HSSP IV (2015-2020) [40]. According to this plan, operationalization of quality improvement ought to be done through the introduction of a performance-based certification system, clients' charters, pay-for-performance (P4P) schemes and an integrated quality improvement program. The latter is supposed to include a national quality improvement toolkit and monitoring system, facility self-assessments and comprehensive supportive supervision, mentoring and coaching [40]. The plan is backedup by a series of basic standards for health facilities at each level of the Tanzanian healthcare system [41-44]. The HSSP IV as well specifies the need for harmonizing, coordinating and integrating the improvement initiatives of the disease specific national control programs [40]. Apart from these initiatives, there are also rather uncoordinated and sometimes duplicative quality improvement approaches from other stakeholders $[16,17,45]$. These approaches rely usually on external assessments conducted in the frame of certification or accreditation procedures, on trainings with subsequent follow-up visits to health facilities or on self-assessments done at health facilities [13, $16,25,46-55]$. To the best of our knowledge, none of the documented approaches looked at routine CHMT supportive supervision. Thus, given the need to improve quality of care and strengthen routine supportive supervision of healthcare providers through their CHMT, we systematically evaluated a new supportive supervision approach that aimed to serve this purpose.

\section{Methods}

\section{Study setting}

The new supportive supervision approach, which was developed as part of the "Initiative to Strengthen Affordability and Quality of Healthcare (ISAQH)", consisted of three stages [56]. In a first step a systematic assessment of quality of primary care was carried out in all health facilities within a given council, using the "electronic Tool to Improve Quality of Healthcare" - in short eTIQH (Fig. 1). CHMT members formed the core of the assessment team. They were supported by community representatives and healthcare providers from the public and private sector. Assessment supervision was done by ISAQH staff. The assessment methods included checklists, structured interviews and direct clinical observations. Importantly, the assessment concluded with an immediate constructive feedback to the healthcare providers and joint discussions about how to address the identified quality gaps. In a second step, a dissemination meeting was held at council level with all relevant stakeholders to discuss the findings and develop action plans. This provided important inputs for the third step, the annual council health planning and budgeting process. 


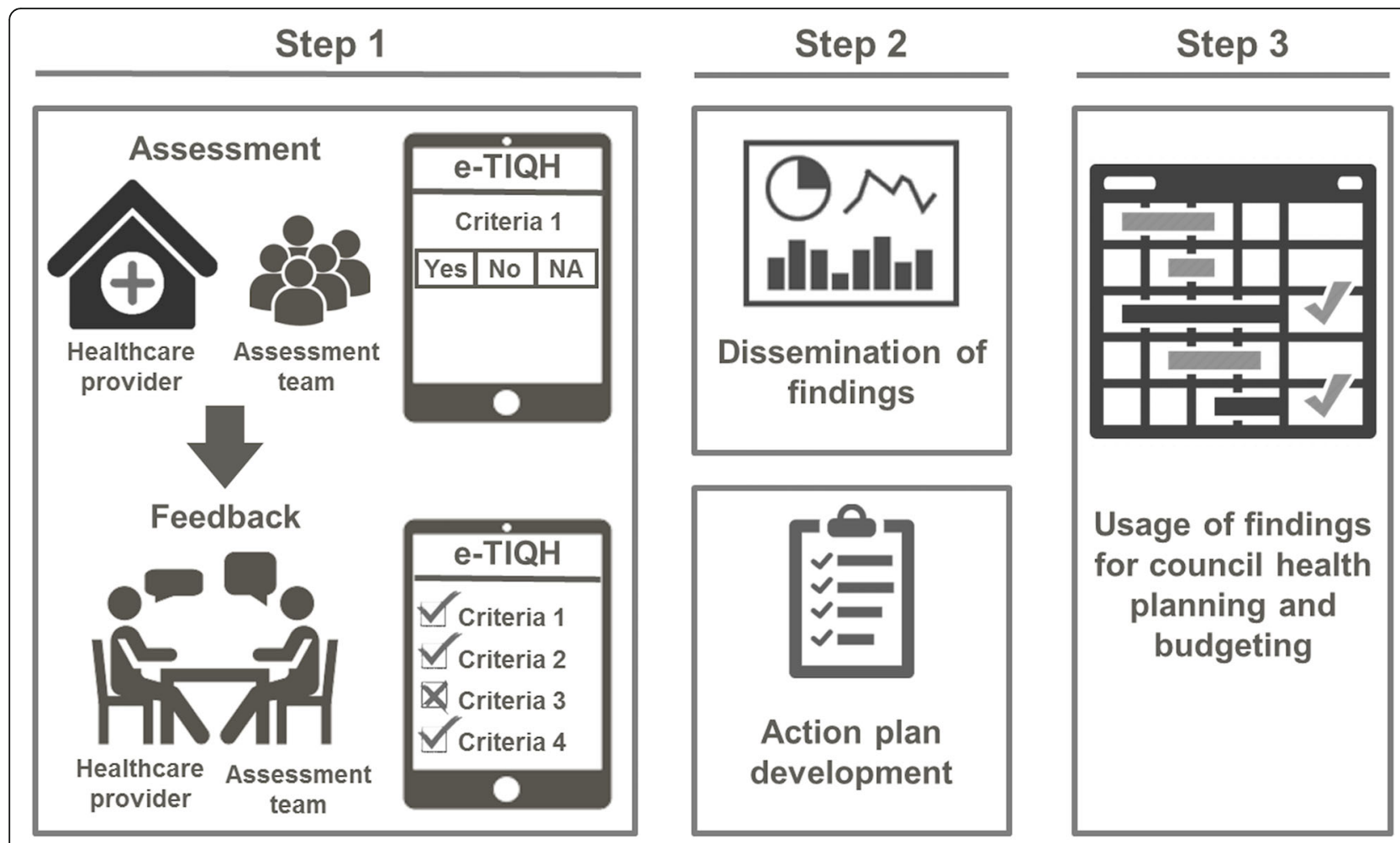

Fig. 1 Chart of the three-stage process of the e-TIQH supportive supervision approach [57]

Using the e-TIQH supportive supervision approach data on quality of primary healthcare was electronically gathered between 2011 and 2014 in health facilities in up to eight Tanzanian district and municipal councils (DCs and MCs) (Fig. 2). Table 1 summarizes the characteristics of the councils. Due to a phased introduction of the e-TIQH approach, the number of assessed councils and health facilities varied from 1 year to the other (Fig. 3).
Kilombero and Ulanga DC were pilot councils for a paper-based version of the same tool. Bagamoyo, Kilosa and Rufiji DC as well as Iringa MC were selected because they had improved health data systems in place thanks to the Sentinel Panel of Districts [59]. Mvomero and Morogoro DC were included due their proximity within the main region of operation. In total, six quality dimensions containing 183 indicators were consistently

Table 1 Description of councils where the e-TIQH supportive supervision approach was implemented (status 2014)

\begin{tabular}{|c|c|c|c|c|c|}
\hline \multirow[t]{2}{*}{ Region/District } & \multirow[t]{2}{*}{ Rural/Urban } & \multirow[t]{2}{*}{ Population [58] } & \multicolumn{3}{|c|}{ Number of health facilities } \\
\hline & & & Dispen-saries & Health centres & Hospita \\
\hline \multicolumn{6}{|l|}{ Morogoro Region } \\
\hline Ulanga DC & Rural & $265^{\prime} 203$ & 33 & 3 & 2 \\
\hline Kilombero DC & Rural & $407 ' 880$ & 52 & 5 & 2 \\
\hline Kilosa/Gairo DC & Rural & 631'186 & 69 & 9 & 3 \\
\hline Mvomero DC & Rural & $312^{\prime} 109$ & 52 & 8 & 3 \\
\hline Morogoro DC & Rural & $286^{\prime} 248$ & 54 & 7 & 0 \\
\hline \multicolumn{6}{|l|}{ Iringa Region } \\
\hline Iringa MC & Urban & $151 ' 345$ & 21 & 4 & 3 \\
\hline \multicolumn{6}{|l|}{ Coast Region } \\
\hline Bagamoyo DC & Rural & $311 ' 740$ & 69 & 5 & 1 \\
\hline Rufiji DC & Rural & $217 ' 274$ & 62 & 5 & 2 \\
\hline Total & & 2'582'985 & 412 & 46 & 16 \\
\hline
\end{tabular}




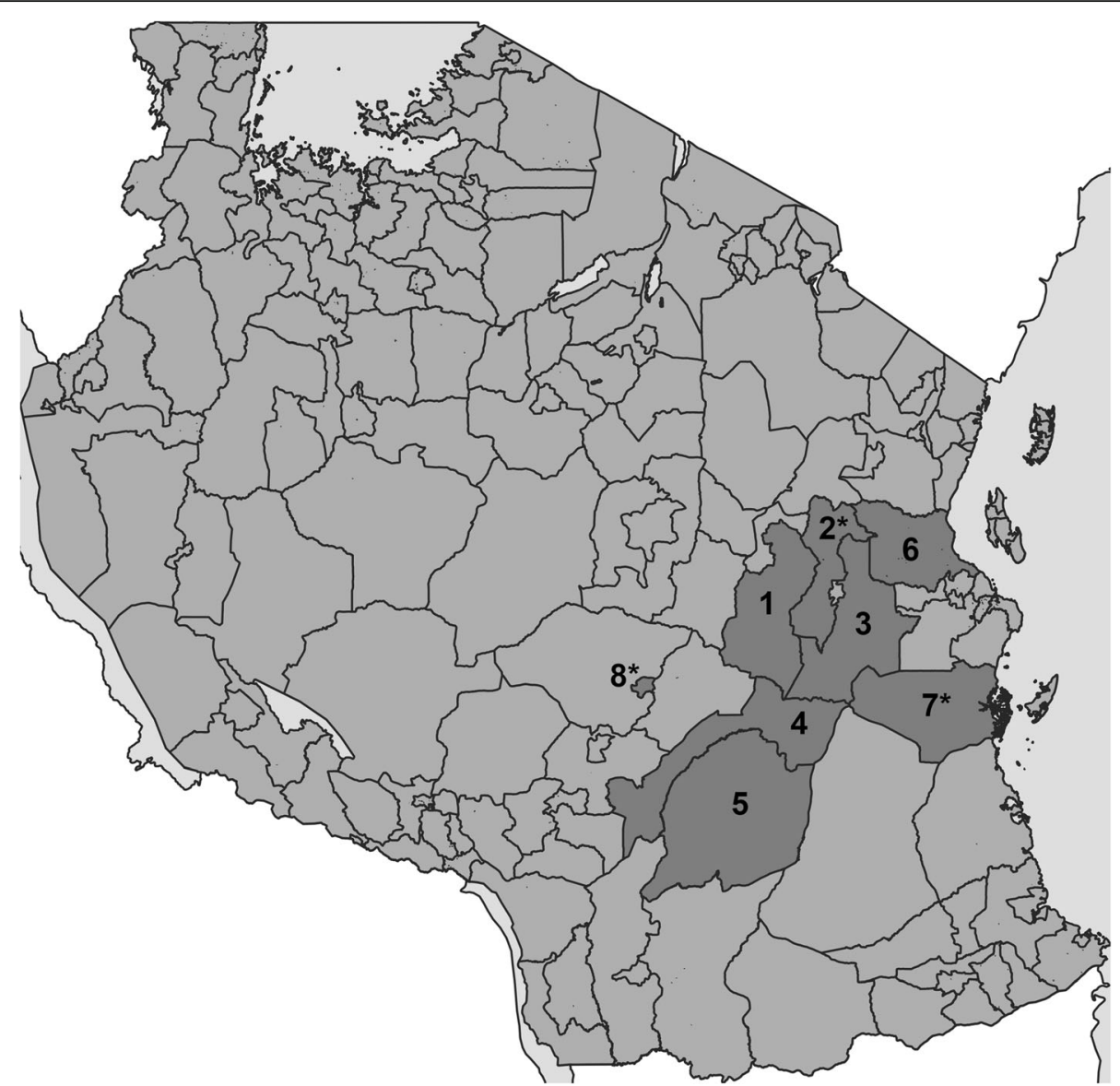

Fig. 2 Map of Tanzania with councils where the e-TIQH supportive supervision approach was implemented (status 2012). Morogoro Region: [1] Kilosa DC (later split into Kilosa and Gairo DC), [2] Mvomero DC, [3] Morogoro DC, [4] Kilombero DC, [5] Ulanga DC; Pwani Region: [6] Bagamoyo DC, [7] Rufiji DC; Iringa Region: [8] Iringa MC. Asterisks mark councils selected for qualitative data collection. Map was generated by the authors using QGIS software and shapefiles obtained from the National Bureau of Statistics in Tanzania

assessed over all 4 years: [1] Physical environment and equipment [2]; Job expectations [3]; Professional knowledge, skills and ethics [4]; Management and administration [5]; Staff motivation [6]; Client satisfaction. The dimensions and indicators were developed in an iterative process by the ISAQH staff together with key stakeholders. This process strictly followed existing national treatment, supportive supervision, and other guidelines [56]. Points were given for each indicator met, and percentage scores (of total possible points) were calculated per quality dimension. The score of each quality dimension then equally contributed to the overall health facility score [56].

\section{Quantitative approach}

To identify the drivers of quality improvements, indicators of the six quality dimensions were further grouped into thematic categories. For each indicator within these thematic categories we also identified the part of the health system, whose primary responsibility it was to address the indicator (Fig. 4). This categorization was done in consultation with a local medical expert familiar with the assessment procedures. Responsibilities could be shared between more than one level, leading to six groups: indicators that primarily ought to be addressed at local (l), council (c) or national (n) level, or in collaboration at local and council $(\mathrm{l} / \mathrm{c})$, council and national $(\mathrm{c} / \mathrm{n})$, or all $(\mathrm{l} / \mathrm{c} / \mathrm{n})$ levels. For public providers, the local level included the staff working at local health facilities and the council and national level the stakeholders acting at council and national level, respectively (e.g. the CHMTs at council level). For private providers, the local level was seen as the staff directly in contact with the client, the council level as the local management level, and the national level as the management at the highest level, e.g. an umbrella institution or owner, which could potentially even be based outside the country. To assess trends over time we calculated the overall score (inner circle, Fig. 4), the six quality dimension scores (middle circle, Fig. 4) and the scores for each thematic category 


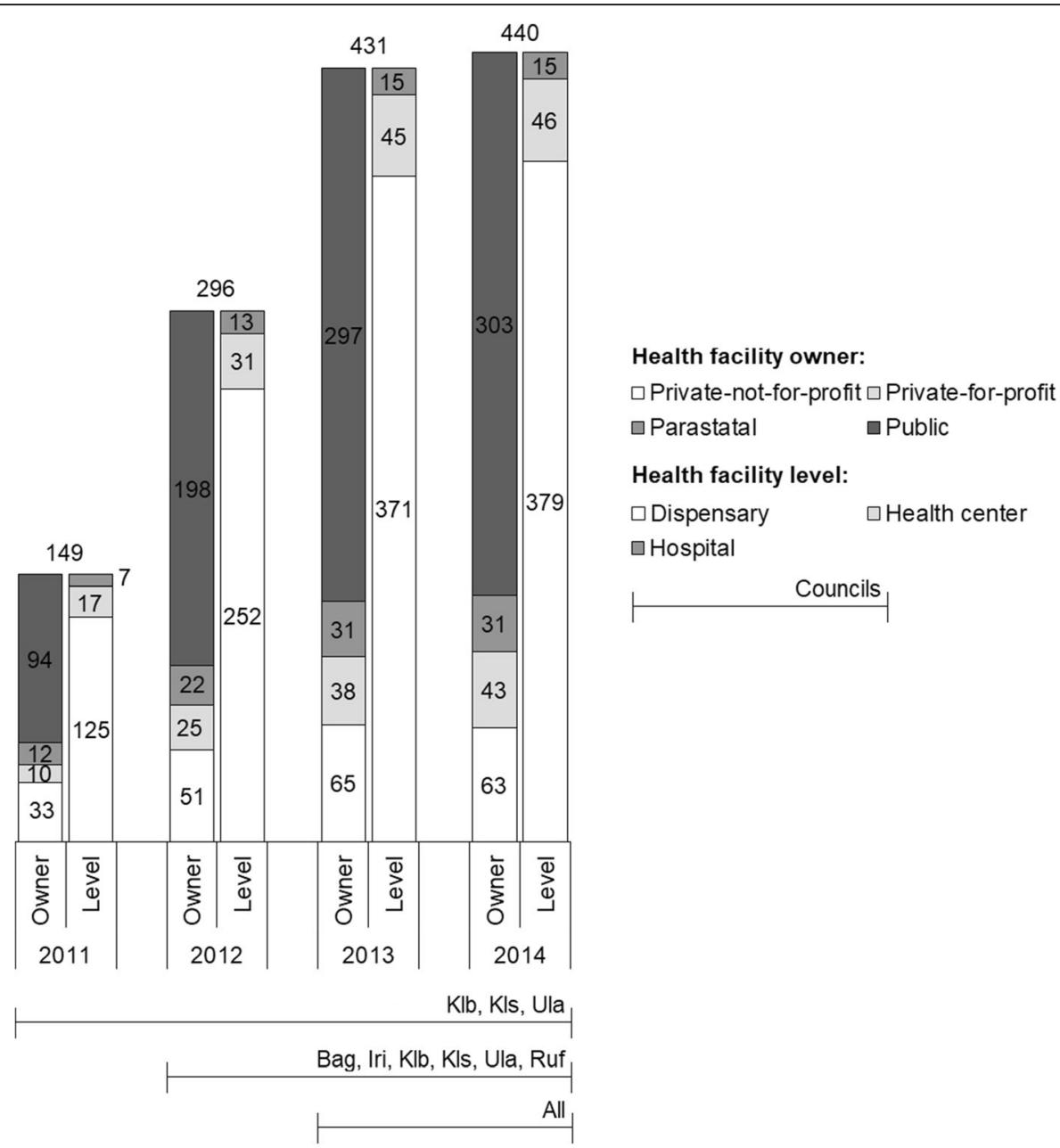

Fig. 3 Number of health facilities assessed in each year by health facility owner and level category across selected councils (horizontal lines at bottom). Bag = Bagamoyo DC, Iri = Iringa MC, Klb= Kilombero DC, Kls = Kilosa DC (later split into Kilosa and Gairo DC), Mor = Morogoro DC, Mvo = Mvomero DC, Ruf = Rufiji DC, Ula $=$ Ulanga DC

by responsible health system level (outer circle, Fig. 4) for every health facility and year. Afterwards mixed linear regression models were derived for each of these scores. Year was included as a categorical variable (2011, 2012, 2013, 2014) and the variable council was set as a random effect. The following equation presents the random effect regression model of the overall score for health facility $\mathrm{i}$ in council $\mathrm{j}$ : HFscore Hij $_{i j}=\beta_{0}+\beta_{1}$ year $2_{i j}+$ $\beta_{2}$ year $_{i j}+\beta_{3}$ year $_{i j}+u_{j}+e_{i j}[1] \mathrm{u}_{\mathrm{j}}$ is the random effect for council and $e_{i j}$ the random effect for health facilities within a council (error term). Regression models for the other scores were in-line with the example given in eq. 1. In a predecessor paper, which used the same database, additional categorical variables (health facility level and health facility owner) as well as third and second order interaction terms were included [60]. The latter were stepwise excluded using Wald test, whereby the variable with the highest order and $p$-value was excluded first.
Models without any interaction terms performed best. In this paper no additional categorical variables were included in order to ease comparing the models for the different scores. Yet, comparisons between the models presented here and models including all additional categorical variables [60] were done to check for differences in significance of coefficients. Also, we did a sensitivity analysis to compare the random effect model (equation 1) with a fixed effect model (equation 2) using the robust variance estimator. HFscore $i j=\beta_{0}+\beta_{1}$ year $2+$ $\beta_{2}$ year $3+\beta_{3}$ year $4+\beta_{4}$ council $2+\beta_{5}$ council $3+\beta_{6}$ council $4+\beta_{7}$ council5 $+\beta_{8}$ council6 $+\beta_{9}$ council7 $+\beta_{10}$ council $8+$ $e_{i j}$ [2] To do so, the relative difference between a given coefficient in the random effect model and the same coefficient in the fixed effect model was calculated for coefficients with a $p$-value lower than 0.05 in at least one of the models. This was done for each coefficient of all regression models. 


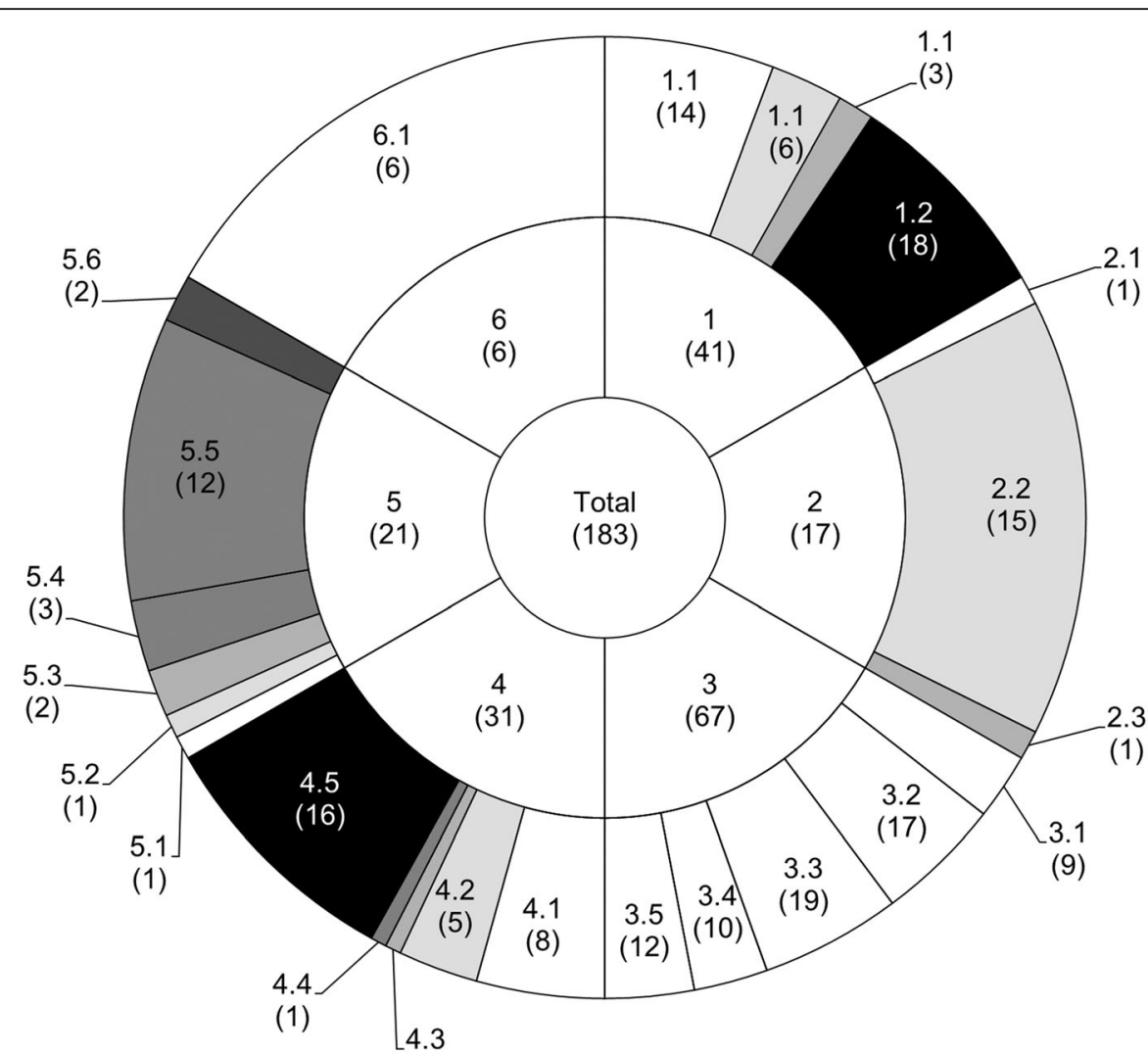

(1)

\section{$\square$ local $\square$ local/council $\square$ council $\square$ council/national unational $\quad$ local/council/national}

Fig. 4 Total number of indicators (inner circle) and the number of indicators per quality dimension (1-6; middle circle) and thematic category by responsible health system level (1.1-6.1; outer circle). Number of indicators is given in brackets. The e-TIQH assessment tool consisted of six quality dimensions contributing equally to the overall score, which is illustrated by the middle circle through equivalent areas of each quality dimension [56]. QD 1 = Physical environment and equipment: QD 1.1 = Physical environment, QD 1.2 = Equipment availability; QD 2 = Job expectations: QD $2.1=$ Provider knowledge of services to be provided, QD 2.2 = Guideline and algorithm availability, QD 2.3= Availability of job description; QD $3=$ Professional knowledge, skills and ethics: QD $3.1=$ Ethics and Infection Prevention and Control (IPC), QD 3.2 = Integrated Management of Childhood IIInesses (IMCI), QD 3.3 = Maternal health, QD 3.4 = Fever, QD 3.5 = HIV/AIDS and TB; QD 4 = Management and administration: QD 4.1 = Display of public information, suggestion box, meeting conduction, duty roster, referral plans, QD 4.2 = Information, Education and Communication (IEC) material availability and Health Management Information System (HMIS) implementation, QD $4.3=$ Routine CHMT supportive supervision visits, QD $4.4=$ Staffing level, QD $4.5=$ Medicines availability; QD 5 = Staff motivation: QD 5.1 = In-house education, QD 5.2 = Appointment as best worker, QD 5.3 = Letter of appreciation and training follow up, QD 5.4 = Reward payment, house allocation, promotion, QD 5.5 = Training, QD 5.6 = Salary and promotion payment; QD $6=$ Client satisfaction

\section{Qualitative approach}

We used qualitative data to support and supplement quantitative findings and to investigate whether and how the eTIQH supportive supervision approach contributed to changes in quality of care. Qualitative data therefore intended to identify areas in which quantitatively captured quality trends could at least to some extent be attributed to the e-TIQH approach. We aimed to strengthen these findings through triangulation of methods and consistency across councils. Alternative methods to assess attribution of quality improvements to the e-TIQH approach were not feasible because this research was analyzing an implementation project. The main part of the qualitative data consisted of in-depth interviews, whereas observational data and informal personal communication recorded in a field notebook as well as materials collected during the field work complemented the data set. A total of 24 in-depth interviews were conducted in three out of eight intervention councils (Fig. 2) because of the limited resources available for this study. However, this did not hamper the quality of the qualitative study because saturation of information was reached prior to the completion of all 24 interviews. Since we aimed to understand reasons for changes in quality of care, the councils with the biggest yearly changes in overall quality (as measured by the e-TIQH assessments) were selected. Sampling coincidentally resulted in the selection of three councils, which were very different in terms of their characteristics (Table 2). This ensured representativeness 
Table 2 Description of councils selected for the qualitative study

\begin{tabular}{|c|c|c|c|}
\hline Characteristics & Rufiji DC & Mvomero DC & Iringa MC \\
\hline Region & Pwani & Morogoro & Iringa \\
\hline Classification & Rural & Rural & Urban \\
\hline Population size [58] & $217^{\prime} 274$ & $312^{\prime} 109$ & $151 ' 345$ \\
\hline Area $\left(\mathrm{km}^{\mathrm{b}}\right)^{\mathrm{a}}$ & $13 \prime 339$ & $7 ' 325$ & 162 \\
\hline Number of operating health facilities [61 $]^{\mathrm{b}}$ & 78 & 69 & 33 \\
\hline Accessibility & $\begin{array}{l}\text { Several hard-to-reach areas, including } \\
\text { the Rufiji river delta }\end{array}$ & Some hard-to-reach areas & No hard-to-reach areas \\
\hline $\begin{array}{l}\text { Existence of pay for performance } \\
\left(\text { P4P) schemes }(20)^{c}\right.\end{array}$ & $\begin{array}{l}\text { Pilot council for donor funded P4P } \\
\text { scheme since } 2011 \text { with focus on } \\
\text { maternal, newborn and child health } \\
\text { services [62] }\end{array}$ & $\begin{array}{l}\text { Partially implemented locally funded } \\
\text { P4P scheme between } 2009 \text { and } 2011 \\
\text { with focus on maternal, newborn and } \\
\text { child health services [63] }\end{array}$ & No P4P experience \\
\hline
\end{tabular}

a Source: Comprehensive Council Health Plans of participating councils collected by SR and IM ${ }^{\mathrm{b}}$ Status October $2016{ }^{\mathrm{C}}$ Result-based financing scheme whereby financial incentives, which are tied to the achievement of service coverage and/or quality improvements, are provided to the healthcare provider

and facilitated drawing conclusions for a wide range of contexts within Tanzania. Sampling of interview partners was done purposefully. At council level two CHMT members (including co-opted members) were interviewed as representatives of the public sector. Additionally, two members of the Council Health Service Board (CHSB), which is the governance body responsible for adequate service delivery and CHMT oversight at council level, were selected to represent the non-public sector [64]. Within the rural councils we selected one public health center and one well and one less well performing public dispensary in terms of quality of care (as measured by the e-TIQH assessments). For the urban council we chose one well and one less well performing dispensary (as measured by the e-TIQH assessments) from the public and the private sector each. Interviews were done with the facility in-charge, and in health centers also with the person responsible for quality improvements (Table 3). Table 4 summarizes some of the demographic characteristics of the respondents. To ensure confidentiality, no further information about the respondents could be given here. For being considered as a respondent, the respondent had to be in the respective position for at least part of the time period in which the e-TIQH approach had been implemented or have comparable experience, based on the interviewers' judgement. Written informed consent

Table 3 Number of in-depth interviews done in the three study councils (Mvomero DC/ Rufiji DC/Iringa MC)

\begin{tabular}{|c|c|c|c|}
\hline \multirow[t]{2}{*}{ Position } & \multirow{2}{*}{$\begin{array}{l}\text { Administrative } \\
\text { level }\end{array}$} & \multicolumn{2}{|l|}{ Sector } \\
\hline & & $\overline{\text { Public }}$ & Non-public \\
\hline CHMT (co-opted) member & Council & $2 / 2 / 2$ & \\
\hline CHSB member & Council & & $2 / 2 / 2$ \\
\hline Health center in-charge & Health center & $1 / 1 / 0$ & \\
\hline Quality improvement person & Health center & $1 / 1 / 0$ & \\
\hline Dispensary in-charge & Dispensary & $2 / 2 / 2$ & $0 / 0 / 2$ \\
\hline Total & & 16 & 8 \\
\hline
\end{tabular}

was obtained from all respondents. Interviews were conducted in the first quarter of 2016. They were done in Swahili and led by a Swahili speaking female Swiss (SR). She was backed up by a male native Tanzanian of middle age (IM). Interviews were guided by the main question relating to whether and how quality of care changed over time and why. It was ensured that respondents clearly refer to a time period in order to assign an event to the timespan before, after or in which the e-TIQH approach had been implemented. It was also probed for specific areas of potential improvements. These areas were based on the health system building blocks (service delivery, health workforce, information/research, healthcare financing, medical product/technology, leadership/governance), as defined by the World Health Organization's health system framework [65]. The health system building blocks were chosen to allow capturing improvements across the whole system, not necessarily only areas included in the e-TIQH assessment tool. The e-TIQH quality dimensions and their thematic categories presented above in Fig. 4 were used as sub-areas within the corresponding building block [65]. Importantly, it was never directly asked if the e-TIQH supportive supervision approach led to certain changes. All interviews were taperecorded and transcribed by two native Tanzanian research assistants but not translated into English. The transcripts were managed and coded with MAXQDA software. Data were analyzed using the framework method described by Gale et al. [66], which uses a structured matrix output to systematically reduce and analyze qualitative data. Coding was primarily done deductively. We used the six health system building blocks as themes. Categories were developed in-line with the e-TIQH thematic categories with space for induction, which allowed creating categories not covered by the e-TIQH assessment tool. Findings were compared for similarities and differences within and between respondent groups. To do so, we took into account the respondent's gender, age, time in the respective 
Table 4 Demographic characteristics of the respondents

\begin{tabular}{|c|c|c|c|c|c|}
\hline & $\begin{array}{l}\text { CHMT member } \\
(n=6)\end{array}$ & $\begin{array}{l}\text { CHSB member } \\
(n=6)\end{array}$ & $\begin{array}{l}\text { Health center in-charge } \\
(n=2)\end{array}$ & $\begin{array}{l}\text { Quality improvement person } \\
(n=2)\end{array}$ & $\begin{array}{l}\text { Dispensary in-charge } \\
(n=8)\end{array}$ \\
\hline \multicolumn{6}{|c|}{ In position since [years] } \\
\hline$<2.5(n=5)$ & 1 & 4 & 0 & 0 & 0 \\
\hline $2.5-4.5(n=8)$ & 2 & 0 & 1 & 1 & 4 \\
\hline $5-7(n=6)$ & 1 & 2 & 0 & 1 & 2 \\
\hline$>7(n=5)$ & 2 & 0 & 1 & 0 & 2 \\
\hline \multicolumn{6}{|l|}{ Gender } \\
\hline male $(n=15)$ & 4 & 5 & 2 & 0 & 4 \\
\hline female $(n=9)$ & 2 & 1 & 0 & 2 & 4 \\
\hline \multicolumn{6}{|l|}{ Age [years] } \\
\hline$<40(n=6)$ & 3 & 0 & 0 & 0 & 3 \\
\hline $40-49(n=3)$ & 0 & 1 & 1 & 0 & 1 \\
\hline $50-59(n=11)$ & 3 & 2 & 1 & 2 & 3 \\
\hline$>59(n=4)$ & 0 & 3 & 0 & 0 & 1 \\
\hline
\end{tabular}

position, position and their working environment (council, health system level and ownership of health facility). Citations used in the text were translated by SR into English and proofread by IM.

\section{Results}

Trends in quality of care as measured by the e-TIQH assessment tool

Differences in average quality dimension (QD) and thematic category scores, expressed as percentages of maximum achievable scores for the years 2012 to 2014 are given in Table 5. These linear regression coefficients indicate how the scores of each quality dimension and thematic category changed compared to the year 2011. The year 2011 percentage score is given by the constant. The sensitivity analysis showed that most coefficients with a $p$-value below 0.05 in the random or fixed effect model were similar to the same coefficient in the other model. The coefficients which differed by more than $10 \%$ of their means are referred to with a hashtag in Table 5. Thus, there was no major difference between the random and fixed effect model using the robust variance estimator. For illustrative purposes, time trends are also shown graphically in Fig. 5 for performance of each quality dimension as well as thematic category and responsible health system level for quality dimension 1 . For quality dimension 1 , which summarized performance in physical environment and equipment, the indicator groups that drove the overall improvement of 3.9 percentage point the most belonged to the category physical environment. These indicators could be addressed either at local level (6.0 percentage point increase) or in collaboration by the local and council level (5.7 percentage point increase). In quality dimension 2, which assessed job expectation, the availability of guidelines and algorithms significantly increased between 2011 and 2014 (4.9 percentage point increase), while trends in the availability of job descriptions went in the opposite direction during the same time period (11.3 percentage point decrease). This resulted in an insignificant overall improvement of 3.7 percentage points. Results of quality dimension 3 revealed that improvements in performance of clinical consultations between 2011 and 2014 varied across categories. They were significant for all types of consultations except when assessing fever cases in patients above 5 years of age. Significant improvements ranged from 4.1 percentage points for maternal health consultations to 20.1 percentage points for HIV/AIDS and TB patients. Quality dimension 4, which represented a broad spectrum of management and administration issues, showed significant positive trends between 2011 and 2014 for the categories capturing medicine availability (8.1 percentage point increase) and things that could be addressed at local level or in collaboration by the local and council level (QD 4.1 11.6 and 4.216 .9 percentage point increase). In quality dimension 5 , which incorporated different types of incentives to boost staff motivation, all categories changed significantly over time. Percentage point increases ranged from 7.5 for appointing best worker and 21.1 for timeliness of salary and promotion payment. Lastly, client satisfaction as measured in quality dimension 6 also indicated a positive trend from 2011 to 2014 with 7.3 percentage point increase.

\section{Contribution of the e-TIQH supportive supervision approach to improvements in quality of care}

A total of 22 out of the 24 respondents directly experienced the e-TIQH approach, either as an assessor, as the person being assessed or during the council dissemination 
Table 5 Differences in average quality dimension (QD) and thematic category scores, expressed as percentages of maximum achievable scores, according to year, while the variable council was set as a random effect

\begin{tabular}{|c|c|c|c|c|c|c|c|}
\hline \multicolumn{8}{|c|}{ Performance by quality dimension (QD) } \\
\hline & Overall & QD 1 & QD 2 & QD 3 & QD 4 & QD 5 & QD 6 \\
\hline 2012 & $3.0^{* *}$ & $-2.9^{*}$ & 1.3 & -1.2 & $5.9^{* * *}$ & $10.6^{* * *}$ & 1.9 \\
\hline 2013 & $6.2^{* * *}$ & -0.9 & $5.4^{*}$ & 2.4 & $6.7^{* * *}$ & $15.8^{* * *}$ & $5.2^{* * *}$ \\
\hline 2014 & $8.0^{* * *}$ & $3.9^{* *}$ & $3.7^{(58)^{\circ}}$ & $6.2^{* * *}$ & $9.9^{* * *}$ & $14.6^{* * *}$ & $7.3^{* * *}$ \\
\hline Constant & $61.6^{* * *}$ & $72.5^{* * *}$ & $52.4^{* * *}$ & $72.3^{* * *}$ & $66.3^{* * *}$ & $31.5^{* * *}$ & $77.4^{* * *}$ \\
\hline
\end{tabular}

QD1: Physical environment and equipment by thematic category and responsible health system level

$\begin{array}{lllll} & \text { QD 1.1, (I) } & \text { QD 1.1, (I/c) } & \text { QD 1.1, (c) } & \text { QD 1.2, (I/c/n }) \\ 2012 & -7.9^{* *} & -5.7^{*} & -2.2 & -0.2 \\ 2013 & 0.7 & -0.2 & -1.3 & -2.1 \\ 2014 & 6.0^{* *} & 5.7^{*} & 4.4 & 1.9 \\ \text { Constant } & 67.4^{* * *} & 70.0^{* * *} & 50.3^{* * *} & 79.3^{* * *}\end{array}$

QD 2: Job expectations by thematic category and responsible health system level

$\begin{array}{llll} & \text { QD2.1, (I) } & \text { QD 2.2, (I/c) } & \text { QD2.3, (c) } \\ 2012 & -2.3 & 0.2 & 15.7^{* * *} \\ 2013 & 1.1 & 5.4^{*} & 7.1 \\ 2014 & 0.4 & 4.9^{*} & -11.3^{* *} \\ \text { Constant } & 97.8^{* * *} & 49.1^{* * *} & 54.6^{* * * i}\end{array}$

QD 3: Professional knowledge, skills and ethics by thematic category and responsible health system level

$\begin{array}{llllll} & \text { QD 3.1, (I) } & \text { QD 3.2, (I) } & \text { QD 3.3, (I) } & \text { QD 3.4, (I) } & \text { QD 3.5, (I) } \\ 2012 & -7.0^{* * *} & -4.3 & 4.3^{*} & -4.8 & 15.6^{* * *} \\ 2013 & -3.5^{*} & 4.4 & 2.2 & 2.4 & 16.0^{* * *} \\ 2014 & 4.4^{* *} & 7.3^{* *} & 4.1^{*} & 2.2 & 20.1^{* * *} \\ \text { Constant } & 78.2^{* * *} & 67.0^{* * *} & 81.7^{* * *} & 66.2^{* * * * i i} & 76.3^{* * *}\end{array}$

QD 4: Management and administration by thematic category and responsible health system level

$\begin{array}{llllll} & \text { QD 4.1, (I) } & \text { QD 4.2, (I/c) } & \text { QD 4.3, (c) } & \text { QD 4.4, (c/n) } & \text { QD 4.5, (I/c/n }) \\ 2012 & -0.6 & 14.1^{* * *} & -9.4^{*} & -1.6 & 8.2^{* * *} \\ 2013 & 3.5 & 15.1^{* * *} & 2.8 & -3.6 & 7.1^{* * *} \\ 2014 & 11.6^{* * *} & 16.9^{* * *} & 5.5 & 6.1 & 8.1^{* * *} \\ \text { Constant } & 53.8^{* * * \text { *Hii }} & 55.2^{* * *} & 84.7^{* * *} & 27.9^{* * * * i v} & 75.7^{* * *}\end{array}$

QD 5: Staff motivation by thematic category and responsible health system level

$\begin{array}{lllllll} & \text { QD 5.1, (I) } & \text { QD 5.2, (I/c) } & \text { QD 5.3, (c) } & \text { QD 5.4, (c/n) } & \text { QD 5.5, (c/n) } & \text { QD 5.6, (n) } \\ 2012 & 7.2 & 2.4 & 8.7^{* *} & 13.1^{* * *} & 10.0^{* * *} & 12.3^{* * *} \\ 2013 & 10.9^{* *} & 4.2^{\# v} & 18.6^{* * *} & 12.6^{* * *} & 16.9^{* * *} & 14.4^{* * *} \\ 2014 & 15.7^{* * *} & 7.5^{* *} & 18.9^{* * *} & 9.2^{* *} & 15.1^{* * *} & 21.1^{* * *} \\ \text { Constant } & 59.8^{* * *} & 7.4^{* * * \mathrm{vi}} & 38.2^{* * *} & 35.3^{* * * * \mathrm{vii}} & 23.5^{* * *} & 67.1^{* * *}\end{array}$

Asterisks refer to $p$-values indicating the significance of a coefficient ${ }^{*} p<0.05,{ }^{* *} p<0.01,{ }^{* * *} p<0.001{ }^{\circ} \mathrm{Coefficient}$ that would have been significant in a model including additional categorical variables (health facility level and health facility owner) but was not in the model presented here [60]. ${ }^{\# C}$ Coefficients with a $p$-value below 0.05 in the random or fixed effect model and which differed by more than $10 \%$ of their means: (i) random: $54.6^{* * *}(p=0.000)$, fixed: $36.0(p=0.000)$; (ii) random: 66.2*** $(p=0.000)$, fixed: $73.3^{* * *}(p=0.000)$; (iii) random: $53.8^{* * *}(p=0.000)$, fixed: $45.1^{* * *}(p=0.000)$; (iv) random: $27.9^{* * *}(p=$ $0.000)$, fixed: $23.8^{* * *}(p=0.000)$; (v) random: $4.2(p=0.102)$, fixed: $4.8^{*}(p=0.038)$ ); (vi) random: $7.4^{* * *}(p=0.006)$, fixed: $2.2(p=0.399)$; (vii) random: $35.3^{* * *}$ $(p=0.000)$, fixed: $31.7^{* * *}(p=0.000)$ There was a large fraction of unexplained variance attributed to the random effect for all models, meaning that scores were strongly correlated within councils (data not shown). Responsible health system levels are given in brackets for easier reference: $I=$ local, $c=$ council; $n=$ national QD 1 = Physical environment and equipment: QD 1.1 = Physical environment, QD 1.2 = Equipment availability; QD 2 = Job expectations: QD 2.1 = Provider knowledge of services to be provided, QD 2.2 = Guideline and algorithm availability, QD 2.3 = Availability of job description; QD $3=$ Professional knowledge, skills and ethics: QD 3.1 = Ethics and Infection Prevention and Control (IPC), QD 3.2 = Integrated Management of Childhood Illnesses (IMCI), QD 3.3 = Maternal health, QD 3.4 = Fever, QD 3.5 = HIV/AIDS and TB; QD 4 = Management and administration: QD 4.1 = Display of public information, suggestion box, meeting conduction, duty roster, referral plans, QD $4.2=$ Information, Education and Communication (IEC) material availability and Health Management Information System (HMIS) implementation, QD 4.3 = Routine CHMT supportive supervision visits, QD 4.4 = Staffing level, QD $4.5=$ Medicines availability; QD 5 = Staff motivation: QD 5.1 = In-house education, QD $5.2=$ Appointment as best worker, QD $5.3=$ Letter of appreciation and training follow up, QD 5.4 = Reward payment, house allocation, promotion, QD 5.5 = Training, QD 5.6 = Salary and promotion payment; QD $6=$ Client satisfaction 


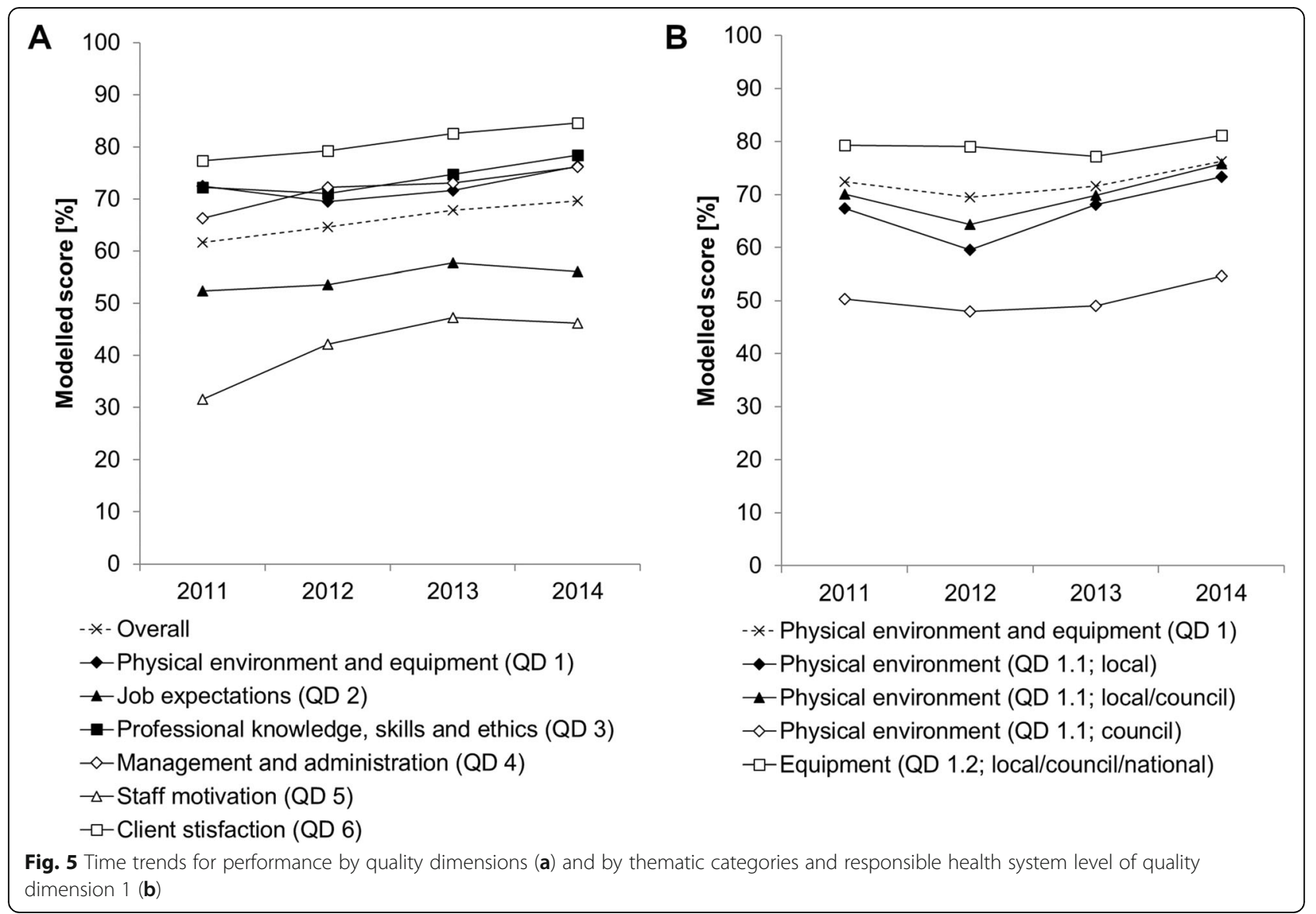

meeting. The subsequent analysis is therefore restricted to these 22 people, because only they could potentially attribute any changes in quality of care to the e-TIQH approach. The following section is structured according to the e-TIQH quality dimensions and focuses on thematic categories in which the e-TIQH supportive supervision approach contributed to improvements. Physical environment and equipment - quality dimension 1 Regarding physical environment and equipment, almost everyone (21 of the 22 included in the analysis) noticed improvements in physical environment. The issues that had been addressed were mostly within the responsibility of the local level, either solely ( 21 of the 21 above mentioned) or in collaboration with the council $(16 / 21)$, and rather less frequent in the hands of the councils (11/21). This was inline with quantitative findings showing significant improvements at local level or in collaboration by the local and council level, but non-significant improvements at council level (Table 5, QD 1.1). Importantly, a considerable number of respondents attributed improvements in physical environment to a large extent to the e-TIQH approach's capability to induce improvement measures (19/21 at local, 11/16 at local/council and 6/11 at council level). A CHMT member summarized this as follows: “... the issue of IPC [Infection Prevention and Control]... was very unsatisfactory...we didn't even have dustbins to dump the waste and also... we didn't do the segregation of it. And when we passed by [at the health facilities] the first time, they put it [the waste] without looking at the color [of the bins]... If you pass by now waste segregation is done and waste is put according to the type of waste. "Routine CHMT supportive supervision, which complements the e-TIQH approach, was also brought up for having contributed to positive changes in physical environment (6/21 at local, 4/16 at local/council and $4 / 11$ at council level). Other than the CHMT supportive supervisions, P4P schemes (Table 2), the CHSB and other stakeholders were stated for having influenced improvements in physical environment. In the case of P4P schemes this was mainly for gaps that had to be addressed at local level or in collaboration by the local and council level. In contrary, other stakeholders were more involved in things that were partially or fully in the responsibility of the council. Improvements in the availability of appropriate equipment were hardly brought up (6/22), which was in agreement with findings in Table 5 (QD 1.2). If so, they were attributed to a mix of interventions, including the e-TIQH 
approach (4/6), the availability of CHF money (2/6), nongovernmental support (1/6) and P4P schemes (1/6). Job expectations - quality dimension 2 For job expectations, a considerable number of respondents (13/22) reported improvements in guideline and algorithm availability, which was concurrent with the quantitative trend (Table 5, QD 2.2). It was explained that the e-TIQH approach $(10 / 13)$ and/or routine CHMT supportive supervision (4/13) identified the lack of latest guidelines and algorithms, upon which healthcare providers and CHMTs started initiatives to increase their availability. This was illustrated by a former facility in-charge as follows: "...we practiced [the procedure] assuming we understand... often we didn't see the importance of having these guidelines, but these guidelines are good. Sometimes you realize... new ones have arrived with changes. It's easy to open and read them. Thus, its [the e-TIQH approach's] job was to remind us that... it's important to have these guidelines. ... and because we were with the CHMT it was easy... He/She [the e-TIQH assessor] told you this guideline you can find there [in the office of the CHMT]... this guideline we don't have, [but] after some days come and look, you will find them [there]. Therefore, it was easy for us to do follow up." Few respondents additionally elaborated that during the eTIQH supportive supervision approach (3/13) and/or trainings $(2 / 13)$ it was emphasized that provided guidelines need to be at work and not at home. Lack of guidelines at council level was seen as the main obstacle for further improvements in this area. Improvements in the availability of job descriptions were barely reported (2/22), which was consistent with the negative trend seen in Table 5 (QD 2.3).Professional knowledge, skills and ethics - quality dimension 3 Changes in performance during clinical consultations as measured by direct observation could have been influenced by several factors, including guideline and algorithm availability, trainings carried out by various stakeholders, as well as supervision visits and in-house education sessions (Table 5, QD 3). These factors therefore have to be accounted for when looking into reasons for improvements of performance during clinical consultations. Half of the respondents $(11 / 22)$ said that the behavior during consultation, in particular friendliness, provider attitude and language used, improved. A majority of the respondents $(8 / 11)$ elaborated that it was the e-TIQH approach's particular emphasis on consultation ethics, which triggered these improvements. Together with the e-TIQH approach, routine CHMT supportive supervision on its own $(2 / 8)$ or in combination with increased availability of guidelines and in-house training $(1 / 8)$ were raised. There were also some (3/11), who mainly attributed changes in ethics to stronger community oversight (2/3) and/or trainings conducted $(2 / 3)$. Apart from consultation ethics, several respondents $(8 / 22)$ reported improvements in compliance with IPC procedures during consultation. All of them $(8 / 8)$ said that the direct observations and subsequent feedback of the e-TIQH approach, which was seen as on-job training, contributed to a great extent to these changes. Lastly, a substantial number of respondents $(15 / 22)$ asserted that treatment guidelines were more closely followed than previously. For example, a facility in-charge said: "... the feedback helped to change us regarding [our] performance because sometimes we forget these steps [of the guidelines], we skip them... we work as we got used to, but... when they [the eTIQH assessors] did this supervision and the way they did it...it changed us a lot." All of them (15/15) acknowledged that the e-TIQH observational approach contributed to these changes. Some also added inhouse training (1/15), trainings conducted by other stakeholders (2/15) and routine CHMT supportive supervision (1/15) were leading to improvements. Interestingly, in one council, routine CHMT supportive supervision was subsequently improved by using the same observational approach. Management and administration - quality dimension 4 With respect to management and administration some respondents reported positive changes in the category capturing things that could be addressed at local level (7/22). They uniquely said that these were triggered by the eTIQH intervention (7/7). However, all other significant improvements in Table 5 were barely due to the e-TIQH approach, but rather because of other interventions. For example, respondents (7/22) acknowledged considerable improvements in respect to the Health Management Information System (HMIS) reporting. Though, none of them mentioned the eTIQH approach for having initiated these changes. They rather stated tight follow up from council level $(4 / 7)$, better health facility internal organization (2/7), increased number of staff (2/7) and improved HMIS system $(2 / 7)$ as reasons for better HMIS reporting. Likewise, better medicine supply was mainly raised $(15 / 22)$ in conjunction with improved supply chain management (7/15) and availability of additional health financing mechanisms $(8 / 15)$, rather than with the e-TIQH approach (2/15). Staff motivation - quality dimension $5 \mathrm{~A}$ considerable number of respondents stated that due to the e-TIQH approach discussions around required measures to improve staff motivation through benefits and rewards were stimulated or reinitiated $(8 / 22)$. In this regard a member of the CHSB said: "It's not that [the] e-TIQH [approach] only showed [us the problems of staff motivation], it stimulated us further [and] made it clearer. The problem however was there since long and people knew it. But... it wasn't an area about which people were complaining... They [the CHMT] may go to facilities and 
start talking about other things, but staff benefits were not spoken about... but [the] e-TIQH [approach] goes as far as asking about staff benefits, you see? The problem was there, but it was not spoken about because it wasn't seen as [the CHMT's] responsibility to ask, but [the] e-TIQH [approach] sees it as its responsibility to ask the personnel. Is he/she satisfied with the work he/she is doing? Is he/she feeling appreciated? Does he/she get the salary on time?" Some improvements were subsequently implemented, whereas the respondents in particular highlighted non-financial benefits. This suggested that the e-TIQH supportive supervision approach potentially contributed to some of the improvements presented in Table 5, QD 5.2, 5.3, and 5.4. In two councils P4P schemes were mentioned $(10 / 22)$ in the context of reward payments. However, despite the positive changes shown in Table 5 complains with regard to benefits and rewards remained high, especially regarding financial employment benefits. According to the respondents the main problems were insufficient and delayed allocation of money from the national level to the councils, and lack of knowledge about administrative procedures at local and council level. For the category "training", some respondents confirmed the positive trends seen in Table $5(3 / 22)$ while others stated the opposite (3/ 22 ), but the e-TIQH approach was hardly brought up in this context. Finally, improvements in timeliness of wage and promotion payments could almost solely be attributed to a revised payment process implemented by the national government as unanimously reported by respondents (Table 5, QD 5.6).

\section{Discussion}

Using a mixed methods approach, we aimed to identify drivers of quality improvements and examine whether the e-TIQH supportive supervision approach was able to contribute to these improvements. The results presented showed that the qualitative and quantitative findings were overlapping and strongly consistent. This strengthened the here identified trends and drivers of quality improvements. It also supported preliminary findings and quality trends documented by Mboya et al. [56] and confirmed what was demonstrated regarding the tool's appropriateness to accurately assess quality of primary healthcare [60].

\section{Contribution of the e-TIQH supportive supervision approach to quality improvements}

Qualitative data identified areas in which the e-TIQH supportive supervision approach contributed to improvements. Advances in physical environment that could be implemented at local level with or without the help of the council could largely be attributed to the e-
TIQH approach. The e-TIQH approach also helped to address issues in physical environment, where the responsibility lied with the councils. The approach could therefore reduce some of the problems around insufficient health infrastructure, poor healthcare waste disposal and low hygiene and sanitation standards [16, 17]. Apart from physical environment, availability of guidelines and algorithms was another category in which improvements were seen in connection with the e-TIQH intervention. Additionally, although acknowledging the likely contribution of trainings conducted by other stakeholders, the direct clinical observations and subsequent feedback of the e-TIQH approach made an important contribution to improved performance during clinical consultations as hypothesized previously [56]. This suggested that the e-TIQH supportive supervision approach not only led to structural changes, but also improved processes. It also demonstrated that measuring process quality by means of observations followed by appropriate immediate feedback positively affected provider practice. In our study, direct observations were highly beneficial for healthcare providers and seen as on-job training, despite the criticism of observations as a process measure [67]. This was in line with what was found and recommended by others in particular in respect to onsite training followup visits [27, 31, 33, 52, 68-71]. Consequently, the knowdo gap and problems with inadequate provider adherence to professional and ethical conduct could be decreased $[16,17]$. For management and administration issues, the e-TIQH approach considerably contributed to the improvements in areas that ought to be addressed at local level. An additional area, which was likely to be positively affected by the e-TIQH approach, was the improved provision of non-financial staff benefits. There, the approach had a crucial role in providing solid evidence about the sensitive topic of staff benefits, and therewith made it possible to officially discuss the issue. This may have reduced the problem of low health worker motivation $[16$, 17]. Overall, we conclude that the e-TIQH supportive supervision approach led to improvements that could be solved at local level, either solely by the healthcare provider or in collaboration with the council. The immediate, supportive feedback followed by solution-oriented discussions with those who were able to address the identified problems was key to the approach. The approach therewith managed to address the lack of feedback on performance upon health facility assessments, as raised previously [14]. This fostered ownership of quality improvement measures at facility level $[16,17]$. Additionally, if the collected data was used appropriately, the e-TIQH approach could also inform improvement measures that needed to be taken at council level. It therefore considerably reduced the problem of poor feedback on quality developments at council level $[16,17]$. Finally, although the e-TIQH 
approach mainly contributed to improvements that required no or little financial means, it facilitated the process of priority setting at local and council level in the light of limited resources.

\section{Contribution of other interventions to quality improvements}

In all the above mentioned improvement processes, healthcare providers and CHMTs were crucial in the implementation of improvement measures. This was because of the participatory e-TIQH approach with strong involvement of local and council stakeholders. Likewise, adoption of the routine CHMT supportive supervision procedures upon exposure to the e-TIQH approach played a key role. This however also meant that contributions made by CHMT supportive supervision could not be clearly distinguished from the direct contributions of the e-TIQH supportive supervision approach as they were complementary. Additionally, revenue collection at health facility level, e.g. through health financing mechanisms and P4P schemes, enabled providers to take and finance actions. This was important for compensating the lack of enough financial means from council and national level to implement the improvement measures at health facility level. It was also in-line with previous findings regarding the use of such kind of revenues [7275]. Observational data further suggested that a selfassessment approach focusing on physical environment (as described by Kamiya et al. [76]) might have as well led to positive changes in physical environment at local level. Improvements in equipment and medicine availability were hardly influenced by the e-TIQH approach as this had largely to be addressed at council and national level and with substantial financial resources. For the same reasons there was no clear contributions of the $\mathrm{e}-\mathrm{TIQH}$ approach to increased numbers of trainings or improvements in management and administration above the local level. Improvements that ought to be addressed at council level also often required considerable financial resources. Here, other stakeholders, especially nongovernmental organizations, seemed to have contributed to these improvements. Lastly, there was no contribution of the e-TIQH approach regarding improved timeliness of salary and promotion payments, or positive changes in staff motivation, that needed a substantial amount of money from national level for its implementation.

\section{Limitations of the study}

It is recognized that well-trained assessors familiar with the context are key for the validity and precision of the assessment and crucial for constructive feedback, an important base for subsequent improvements. In the case of direct observations, a Hawthorne effect could not be excluded [77-79]. We further acknowledge that the presented regression models could have been improved by including additional variables and potentially significant interaction terms. However, comparing the models presented here and models including all additional variables [60] did not lead to a difference in significance of coefficients. Additionally, although conclusions presented here were supported by the triangulation of methods, we recognize that causality cannot conclusively be claimed. Unknown factors might have also contributed to the observed results. We also could not fully exclude that the improvements seen were driven by the choice of the indicators included in the e-TIQH tool, which might have led to overestimation of real changes. The respondents were aware that the interviewers knew the team who facilitated the implementation of the e-TIQH supportive supervision approach. This could have potentially led to statements overestimating the contribution of the e-TIQH approach. Moreover, it was not part of the analysis presented here to investigate improvements in quality of care which were not quantitatively captured through e-TIQH assessments. This included contributions of other stakeholders, and additional benefits of the overall e-TIQH supportive supervision approach, like increased staff motivation owing to appropriate feedback given at health facility. The latter will be discussed in a forthcoming paper, which aims to compare the e-TIQH approach with routine CHMT supportive supervision as it is currently implemented [57]. It was also beyond the scope of this analysis to examine the effects of the e-TIQH-linked quality improvements on changes in health outcomes. Hence, the proof that improved processes lead to improved outcomes could be subject of further research, for example through connecting community health data with health facility data.

\section{Conclusions}

The results clearly demonstrated that the e-TIQH supportive supervision approach not only served to assess quality of primary healthcare, but also to address quality issues that laid within the responsibility of the councils or the health facilities. Hence, the e-TIQH approach was able to improve and maintain crucial primary healthcare quality standards across different health facility level and owner categories in various contexts. It also managed to address several major quality issues outlined in the $\mathrm{Na}$ tional Health and Social Welfare Quality Improvement Strategic Plan [17]. To the best of our knowledge this is currently the only approach to directly strengthen routine CHMT supportive supervision in Tanzania that has demonstrated such direct impact on general quality of primary care. The e-TIQH approach therefore presents a powerful tool to support, guide and drive quality improvement measures within councils. It can thus be considered a suitable option to make routine supportive supervision more effective and adequate. 


\section{Abbreviations}

CHMT: Council Health Management Team; CHSB: Council Health Service Board; DC: District Council; e-TIQH: electronic Tool to Improve Quality of Healthcare; HMIS: Health Management Information System; HSSP: Health Sector Strategic Plan; IEC: Information, Education and Communication; IMCI: Integrated Management of Childhood IIness; IPC: Infection Prevention and Control; MC: Municipal Council; NIMR: National Institute for Medical Research; P4P: Pay-for-Performance; QD: Quality dimension; UHC: Universal Health Coverage

\section{Acknowledgements}

We thank the councils that participated in our study, especially the study participants. The authors also thank Dr. Christian Schindler for his statistical support. We additionally acknowledge Sylvia Daulinge for the transcription of interviews. Further, we appreciate logistic support provided by Dominik Shamba during the study implementation.

\section{Authors' contributions}

SR, IM, DM, CM, FK, TG, CL, AS, and CP conceptualized the study. SR, DM, and CC were involved in data curation. SR, IM, and TG did the formal analysis of the study. AA and $C L$ acquired funding. SR and IM conducted the investigations. SR, IM, DM, FK, TG, CL, and CP developed or designed the methodology. SR, FK, and CL administered the project. DM, CC, and FK provided study materials. SR, DM, CC, CM, FK, CL, and AS contributed to the software development. FK, CL, and CP supervised the research activities. FK, $\mathrm{TG}, \mathrm{CP}$, and $\mathrm{CL}$ validated the results. SR prepared the visualization of the published work. SR wrote the first draft of the publication and SR, IM, DM, $C C, C M, F K, T G, C L, A S, A A$, and $C P$ reviewed and edited it subsequently. All authors have read and approved the manuscript.

\section{Funding}

Novartis Foundation fully funded this study. Novartis Foundation had no role in the design of the study, neither in the collection, analysis, and interpretation of data nor in writing the manuscript. However, the author (AA), who is working for the funding body (Novartis Foundation), reviewed and edited the final manuscript.

\section{Availability of data and materials}

The quantitative dataset used and analyzed during the current study are available from the corresponding author on reasonable request. The qualitative dataset generated and analyzed during the current study are not publicly available as individual privacy of the respondents could be compromised but are available from the corresponding author on reasonable request.

\section{Ethics approval and consent to participate}

Permission to publish the findings was obtained from the National Institute for Medical Research (NIMR) in Tanzania. Human ethics guidelines were complied with. Ethical clearance for e-TIQH data collection was granted by NIMR (NIMR/HQ/R.8a/NOL.IX/236) and the Institutional Review Board of the Ifakara Health Institute (IHRDC/IRB/No.A:018) in 2003. The evaluation of the eTIQH approach was cleared by NIMR (original: NIMR/HQ/R.8a/Nol.IX/1839, extension: NIMR/HQ/R.8c/Nol.II/521) and the Institutional Review Board of the Ifakara Health Institute (IHI/RB/No:37-2014) in October 2014 as well as the Ethic Commission of Northeast and Central Switzerland (EKNZ 2014-347) in November 2014. Written informed consent was obtained from all respondents.

\section{Consent for publication}

\section{Not applicable.}

\section{Competing interests}

AA is working for the funding body (Novartis Foundation). All other authors declare that they have no competing interests.

\section{Author details}

'Department of Epidemiology and Public Health, Swiss Tropical and Public Health Institute, P.O. Box, 4002, Basel, Switzerland. 'University of Basel, Basel, Switzerland. ${ }^{3}$ Ifakara Health Institute, Dar es Salaam/Ifakara, United Republic of Tanzania. ${ }^{4}$ Swiss Agency for Development and Cooperation, Berne, Switzerland. ${ }^{5}$ Novartis Foundation, Basel, Switzerland.
Received: 7 January 2019 Accepted: 16 October 2019

Published online: 20 November 2019

\section{References}

1. World Health Organization. The world health report: health system financing. Geneva: World Health Organisation; 2010.

2. GBD 2016 Healthcare Access and Quality Collaborator. Measuring performance on the Healthcare Access and quality index for 195 countries and territories and selected subnational locations: a systematic analysis from the global burden of disease study 2016. Lancet. 2018;391(10136):2236-71.

3. Sustainable Development Solution Network. Indicators and a monitoring framework for the sustainable development goals. United Nations: Sustainable Development Solution Network; 2015.

4. Akachi Y, Tarp F, Kelley E, Addisona T, Kruk ME. Measuring quality-of-care in the context of sustainable development goal 3: a call for papers. Bull World Health Organ. 2016;94(3):160-A.

5. Souza JP, Gulmezoglu AM, Vogel J, Carroli G, Lumbiganon P, Qureshi Z, et al. Moving beyond essential interventions for reduction of maternal mortality (the WHO multicountry survey on maternal and newborn health): a cross-sectional study. Lancet. 2013;381(9879):1747-55.

6. Powell-Jackson T, Mazumdar S, Mills A. Financial incentives in health: new evidence from India's Janani Suraksha Yojana. J Health Econ. 2015;43:154-69.

7. Godlonton S, Okeke EN. Does a ban on informal health providers save lives? Evidence from Malawi. J Dev Econ. 2016;118:112-32.

8. Chari AV, Okeke EN. Can institutional deliveries reduce newborn mortality? Evidence from Rwanda. Rand Labor \& Population: Rand Cooperation; 2014

9. Boerma T, Eozenou P, Evans D, Evans T, Kieny MP, Wagstaff A. Monitoring progress towards universal health coverage at country and global levels. PLoS Med. 2014;11(9):e1001731.

10. Kruk ME, Kelley E, Syed SB, Tarp F, Addison T, Akachi Y. Measuring quality of health-care services: what is known and where are the gaps? Bull World Health Organ. 2017;95(6):389-A.

11. The Lancet. The struggle for universal health coverage. Lancet. 2012; 380(9845):859.

12. Ruelas E, Gomez-Dantes O, Leatherman S, Fortune T, Gay-Molina JG Strengthening the quality agenda in health care in low- and middle-income countries: questions to consider. Int J Qual Health Care. 2012;24(6):553-7.

13. Johnson MC, Schellekens O, Stewart J, van Ostenberg P, de Wit TR, Spieker N. SafeCare: an innovative approach for improving quality through standards, benchmarking, and improvement in low- and middle- income countries. Jt Comm J Qual Patient Saf. 2016:42(8):350-71.

14. Edward A, Matsubiyashi T, Fapohunda B, Becker S. A comparative analysis of select health facility survey methods applied in low and middle income countries [working paper WP-09-11]. Chapel Hill, NC: MEASURE Evaluation; 2009.

15. Nickerson JW, Adams O, Attaran A, Hatcher-Roberts J, Tugwell P. Monitoring the ability to deliver care in low- and middle-income countries: a systematic review of health facility assessment tools. Health Policy Plan. 2014;30(5):675-86.

16. Ministry of Health and Social Welfare. The Tanzania Quality Improvement Framework in Health Care 2011-2016. Dar es Salaam: Ministry of Health and Social Welfare, United Republic of Tanzania; 2011.

17. Ministry of Health and Social Welfare. National Health and Social Welfare Quality Improvement Strategic Plan 2013-2018. Dar es Salaam: Ministry of Health and Social Welfare, United Republic of Tanzania; 2013.

18. Leonard KL, Masatu MC. Professionalism and the know-do gap: exploring intrinsic motivation among health workers in Tanzania. Health Econ. 2010; 19(12):1461-77.

19. Ministry of Health and Social Welfare. Mid Term Review of the Health Sector Strategic Plann III 2009-2015: Captial investment. Dar es Salaam: Ministry of Health and Social Welfare, United Republic of Tanzania; 2013.

20. Olafsdottir AE, Mayumana I, Mashasi I, Njau I, Mamdani M, Patouillard E, et al. Pay for performance: an analysis of the context of implementation in a pilot project in Tanzania. BMC Health Serv Res. 2014;14:392.

21. Manongi RN, Marchant TC, Bygbjerg IC. Improving motivation among primary health care workers in Tanzania: a health worker perspective. Hum Resour Health. 2006;4:6.

22. McAuliffe E, Daly M, Kamwendo F, Masanja H, Sidat M, de Pinho H. The critical role of supervision in retaining staff in obstetric services: a three country study. PLoS One. 2013;8(3):e58415.

23. Mubyazi GM, Bloch P, Byskov J, Magnussen P, Bygbjerg IC, Hansen KS Supply-related drivers of staff motivation for providing intermittent 
preventive treatment of malaria during pregnancy in Tanzania: evidence from two rural districts. Malar J. 2012;11:48.

24. Manzi F, Schellenberg JA, Hutton G, Wyss K, Mbuya C, Shirima K, et al. Human resources for health care delivery in Tanzania: a multifaceted problem. Hum Resour Health. 2012;10:3.

25. Nangawe E. Situation Analysis of Quality Improvement in Health Care, Tanzania. Dar es Salaam: Ministry of Health and Social Welfare, United Republic of Tanzania; 2012.

26. Ministry of Health and Social Welfare. National Supportive Supervison Guideline for Quality Healthcare Services. Dar es Salaam: Ministry of Health and Social Welfare, United Republic of Tanzania; 2010.

27. Prytherch H, Kakoko DC, Leshabari MT, Sauerborn R, Marx M. Maternal and newborn healthcare providers in rural Tanzania: in-depth interviews exploring influences on motivation, performance and job satisfaction. Rural Remote Health. 2012;12:2072.

28. Hoque DM, Arifeen SE, Rahman M, Chowdhury EK, Haque TM, Begum K, et al. Improving and sustaining quality of child health care through IMCI training and supervision: experience from rural Bangladesh. Health Policy Plan. 2014;29(6):753-62.

29. Bello DA, Hassan Zl, Afolaranmi TO, Tagurum YO, Chirdan OO, Zoakah Al. Supportive supervision: an effective intervention in achieving high quality malaria case management at primary health care level in Jos. Nigeria Ann Afr Med. 2013;12(4):243-51.

30. Frimpong JA, Helleringer S, Awoonor-Williams JK, Yeji F, Phillips JF. Does supervision improve health worker productivity? Evidence from the upper east region of Ghana. Tropical Med Int Health. 2011;16(10):1225-33.

31. Suh S, Moreira P, Ly M. Improving quality of reproductive health care in Senegal through formative supervision: results from four districts. Hum Resour Health. 2007:5:26.

32. Bailey C, Blake C, Schriver M, Cubaka VK, Thomas T, Martin HA. A systematic review of supportive supervision as a strategy to improve primary healthcare services in sub-Saharan Africa. Int J Gynaecol Obstet. 2016;132(1): 117-25.

33. Kiplagat A, Musto R, Mwizamholya D, Morona D. Factors influencing the implementation of integrated management of childhood illness (IMCI) by healthcare workers at public health centers \& dispensaries in Mwanza, Tanzania. BMC Public Health. 2014;14:277.

34. Zinnen V, Paul E, Mwisongo A, Nyato D, Robert A. Motivation of human resources for health: a case study at rural district level in Tanzania. Int J Health Plann Manag. 2012;27(4):327-47.

35. Rowe AK, de Savigny D, Lanata CF, Victora CG. How can we achieve and maintain high-quality performance of health workers in low-resource settings? Lancet. 2005;366(9490):1026-35.

36. Lazzerini M, Shukurova V, Davletbaeva M, Monolbaev K, Kulichenko T, Akoev $Y$, et al. Improving the quality of hospital care for children by supportive supervision: a cluster randomized trial, Kyrgyzstan. Bull World Health Organ. 2017;95(6):397-407.

37. Madede T, Sidat M, McAuliffe E, Patricio SR, Uduma O, Galligan M, et al. The impact of a supportive supervision intervention on health workers in Niassa, Mozambique: a cluster-controlled trial. Hum Resour Health. 2017;15(1):58.

38. Clements CJ, Streefland PH, Malau C. Supervision in primary health care-can it be carried out effectively in developing countries? Curr Drug Saf. 2007;2(1):19-23.

39. Ministry of Health and Social Welfare. Health sector strategic plan III: July 2009 - June 2015. Dar es Salaam: Ministry of Health and Social Welfare, Uneited Republic of Tanzania; 2009.

40. Ministry of Health and Social Welfare. Health Sector Strategic Plan (HSSP IV): July 2015-June 2020. Dar es Salaam: Ministry of Health and Social Welfare, United Republic of Tanzania; 2015.

41. Ministry of Health Community Development Gender Elderly and Children: Basic Standards for Health Facilities: Household and Community Level. Edited by Health Quality Assurance Division, vol. 1. Dar es Salaam: Ministry of Health, Community Development, Gender, Elderly and Children, United Republic of Tanzania; 2017

42. Ministry of Health Community Development Gender Elderly and Children: Basic Standards for Health Facilities: Dispensaries, Health Centres, Stand Alone Dental Clinics and Rehabilitation Medicine Facilities. Edited by Division HQA, vol. 2. Dar es Salaam: Ministry of Health, Community Development, Gender, Elderly and Children, United Republic of Tanzania; 2017.

43. Ministry of Health Community Development Gender Elderly and Children: Basic Standards for Health Facilities: Hospitals at Level I \& II and Stand Alone
Facilities at Level I \& II. In. Edited by Division HQA, vol. 3. Dar es Salaam: Ministry of Health, Community Development, Gender, Elderly and Children, United Republic of Tanzania; 2017.

44. Ministry of Health Community Development Gender Elderly and Children: Basic Standards for Health Facilities: Hospital at Level III \& IV and Specialised Clinics at Level III. In. Edited by Division HQA, vol. 4. Dar es Salaam: Ministry of Health, Community Development, Gender, Elderly and Children, United Republic of Tanzania; 2017.

45. Mwidunda PE, Eliakimu E. Creating a national culture of quality: the Tanzania experience. AIDS. 2015;29(Suppl 2):S175-7.

46. Bradley J, Igras S. Improving the quality of child health services: participatory action by providers. Int J Qual Health Care. 2005;17(5):391-9.

47. Kanamori S, Shibanuma A, Jimba M. Applicability of the 5 S management method for quality improvement in health-care facilities: a review. Trop Med Health. 2016:44:21.

48. Ministry of Health and Social Welfare. BRN Healthcare NKRA Lab. Dar es Salaam: Ministry of Health and Social Welfare, United Republic of Tanzania; 2015.

49. Ministry of Health and Social Welfare. National Infection Prevention and Control Standards for Hospitals in Tanzania. Dar es Salaam: Ministry of Health and Social Welfare, United Republic of Tanzania; 2012.

50. Necochea E, Tripathi V, Kim YM, Akram N, Hyjazi Y, da Luz VM, et al. Implementation of the standards-based management and recognition approach to quality improvement in maternal, newborn, and child health programs in lowresource countries. Int J Gynaecol Obstet. 2015;130(Suppl 2):S17-24.

51. Dohlie MB, Mielke E, Bwire T, Adriance D, Mumba F. COPE (client-oriented, provider-efficient), a model for building community partnerships that improve care in East Africa. J Healthc Qual. 2000;22(5):34-9.

52. Jaribu J, Penfold S, Manzi F, Schellenberg J, Pfeiffer C. Improving institutional childbirth services in rural southern Tanzania: a qualitative study of healthcare workers' perspective. BMJ Open. 2016;6(9):e010317.

53. Tanzania Spread Study Team. Spread of PMTCT and ART Better Care Practices through Collaborative Learning in Tanzania. Bethesda, MD: USAID Health Care Improvement Project, University Research Co., LLC (URC); 2011.

54. Hanson C, Waiswa P, Marchant T, Marx M, Manzi F, Mbaruku G, et al. Expanded quality management using information power (EQUIP): protocol for a quasi-experimental study to improve maternal and newborn health in Tanzania and Uganda. Implement Sci. 2014;9(1):41.

55. Jaribu J, Penfold S, Green C, Manzi F, Schellenberg J. Improving Tanzanian childbirth service quality. Int J Health Care Qual Assur. 2018;31(3):190-202.

56. Mboya D, Mshana C, Kessy F, Alba S, Lengeler C, Renggli S, et al. Embedding systematic quality assessments in supportive supervision at primary healthcare level: application of an electronic tool to improve quality of Healthcare in Tanzania. BMC Health Serv Res. 2016;16(1):578.

57. Renggli S, Mayumana I, Mboya D, Charles C, Maeda J, Mshana C, et al. Towards improved health service quality in Tanzania: an approach to increase efficiency and effectiveness of routine supportive supervision. PLoS One. 2018;13(9):e0202735.

58. National Bureau of Statistics. 2012 Population and housing census. Dar es Salaam: National Bureau of Statistics, Ministry of Finance, United Republic of Tanzania; 2013.

59. Ifakara Health Institute. Sentinel Panel of Districts: A new platform for health monitoring and evaluation in Tanzania. Ifakara Health Institute Spotlight. 2011.

60. Renggli S, Mayumana I, Mboya D, Charles C, Mshana C, Kessy F, et al. Towards improved health service quality in Tanzania: appropriateness of an electronic tool to assess quality of primary healthcare. BMC Health Serv Res. 2019;19(1):55.

61. Health Facility Registry. Ministry of Health, Community Development, Gender, Elderly and Children, United Republic of Tanzania; 2016. http:// hfrportal.ehealth.go.tz/. Accessed 7 Oct 2016.

62. Chimhutu V, Songstad NG, Tjomsland M, Mrisho M, Moland KM. The inescapable question of fairness in pay-for-performance bonus distribution: a qualitative study of health workers' experiences in Tanzania. Glob Health. 2016;12(1):77.

63. Chimhutu V, Lindkvist I, Lange S. When incentives work too well: locally implemented pay for performance (P4P) and adverse sanctions towards home birth in Tanzania - a qualitative study. BMC Health Serv Res. 2014;14:23.

64. Kessy F, Mtei G, Mbwambo J, Manumbu K, Mbuya D. Technical Review of Council Health Service Boards and Health Facility Geoverning Committees in Tanzania; 2008.

65. World Health Organization. Everybody's business: strengthening health systems to improve health outcomes available. Geneva: World Health Organization; 2007. 
66. Gale NK, Heath G, Cameron E, Rashid S, Redwood S. Using the framework method for the analysis of qualitative data in multi-disciplinary health research. BMC Med Res Methodol. 2013;13:117.

67. Peabody JW, Taquiwalo MM, Robalino DA, Frenk J. Improving the Quality of Care in Developing Countries. In: Jamison DT, Breman JG, Measham AR, Alleyne G, Claeson M, Evans DB, et al., editors. Disease Control Priorities in Developing Countries. 2nd ed. Washington (DC): The World Bank; 2006.

68. Manzi A, Magge H, Hedt-Gauthier BL, Michaelis AP, Cyamatare FR, Nyirazinyoye L, et al. Clinical mentorship to improve pediatric quality of care at the health centers in rural Rwanda: a qualitative study of perceptions and acceptability of health care workers. BMC Health Serv Res. 2014;14:275.

69. Edward A, Dam K, Chege J, Ghee AE, Zare H, Chhorvann C. Measuring pediatric quality of care in rural clinics-a multi-country assessmentCambodia, Guatemala, Zambia and Kenya. Int J Qual Health Care. 2016; 28(5):586-93.

70. Heiby J. The use of modern quality improvement approaches to strengthen African health systems: a 5-year agenda. Int J Qual Health Care. 2014;26(2): $117-23$

71. Leonard KL, Masatu MC. Changing health care provider performance through measurement. Soc Sci Med. 2017;181:54-65.

72. Binyaruka P, Patouillard E, Powell-Jackson T, Greco G, Maestad O, Borghi J. Effect of paying for performance on utilisation, quality, and user costs of health Services in Tanzania: a controlled before and after study. PLoS One. 2015;10(8):e0135013.

73. Mtei G, Mulligan JA. Community Health Funds in Tanzania: A literature review. Dar es Salaam: Consortium for Research on Equitable Health Systems, Ifakara Health Institute; 2007.

74. Maluka SO, Bukagile G. Implementation of community health Fund in Tanzania: why do some districts perform better than others? Int J Health Plann Manag. 2014;29(4):e368-82.

75. Binyaruka P, Borghi J. Improving quality of care through payment for performance: examining effects on the availability and stock-out of essential medical commodities in Tanzania. Tropical Med Int Health. 2017;22(1):92-102

76. Kamiya Y, Ishijma H, Hagiwara A, Takahashi S, Ngonyani HA, Samky E. Evaluating the impact of continuous quality improvement methods at hospitals in Tanzania: a cluster-randomized trial. Int J Qual Health Care. 2017;29(1):32-9.

77. Campbell JP, Maxey VA, Watson WA. Hawthorne effect: implications for prehospital research. Ann Emerg Med. 1995;26(5):590-4.

78. Leonard K, Masatu MC. Outpatient process quality evaluation and the Hawthorne effect. Soc Sci Med. 2006;63(9):2330-40.

79. McCambridge J, Witton J, Elbourne DR. Systematic review of the Hawthorne effect: new concepts are needed to study research participation effects. J Clin Epidemiol. 2014;67(3):267-77.

\section{Publisher's Note}

Springer Nature remains neutral with regard to jurisdictional claims in published maps and institutional affiliations.

\section{Ready to submit your research? Choose BMC and benefit from:}

- fast, convenient online submission

- thorough peer review by experienced researchers in your field

- rapid publication on acceptance

- support for research data, including large and complex data types

- gold Open Access which fosters wider collaboration and increased citations

- maximum visibility for your research: over $100 \mathrm{M}$ website views per year

At $\mathrm{BMC}$, research is always in progress.

Learn more biomedcentral.com/submissions 